\section{FOLLOW-UP 25OHD LEVELS IN PRETERM VERY LOW BIRTH WEIGHT (VLBW) INFANTS}

R.A. McCarthy ${ }^{1}$, M.M. McKenna², J.F. Murphy ${ }^{1}$, A. Twomey ${ }^{1}$, J. Brady' ${ }^{2}$ B. Murray ${ }^{2}$, N. Murphy ${ }^{3}$, O. Uduma ${ }^{1}$, E.J. Molloy ${ }^{1,4,5}$

${ }^{1}$ Department of Neonatology, National Maternity Hospital, '2Metabolism Laboratory, St Vincent's University Hospital, ${ }^{3}$ Endocrinology, Children's University Hospital, ${ }^{4}$ School of Medicine and Medical Sciences, University College Dublin,

${ }^{5}$ Royal College of Surgeons in Ireland, Dublin, Ireland

Background and aim: Vitamin D plays an important role in skeletal and non-skeletal health. In preterm VLBW infants, we previously reported a high prevalence (about $80 \%$ ) of vitamin D insufficiency, defined as a serum 25-hydroxyvitamin D (25OHD) $<50 \mathrm{nmol} / \mathrm{L}$. The aim of this study was to re-assess $250 H D$ status in those infants who had a level < $50 \mathrm{nmol} / \mathrm{l}$, following augmented vitamin D intake.

Methods: Preterm or VLBW infants $(n=109)$, who had an initial serum $250 \mathrm{OHD}$ level $<50 \mathrm{nmol} / \mathrm{L}$ during NICU admission, were re-assessed after advice to ensure vitamin $D_{3}$ intakes of $\geq 400$ IU daily from feeds and supplements.

Results: Infants were re-assessed at mean day of life 170 (median 119, range 15-711), or mean postconceptual age (PCA) 53.6wks (median 47.6, range 30.7-127.6). Using a recent classification of vitamin D status[i], we noted that $26(24 \%)$ remained $<50$ $\mathrm{nmol} / \mathrm{L}$ (insufficient); $83(76 \%)$ were $\geq 50 \mathrm{nmol} / \mathrm{L}$ (sufficient); and 40(37\%)were $\geq 80 \mathrm{nmol} / \mathrm{L}$ (desirable). There was a significant correlation between followup 25OHD and PCA $(r=0.27 ; p=0.004)$, and day of life $(r=0.24 ; p=0.013)$, but not with ethnicity, gender, gestation at birth, birth weight, or initial $250 \mathrm{HD}$. A forward multiple regression model identified PCA as the sole predictor of follow-up $250 H D\left(r^{2}=0.08\right.$; $\mathrm{p}=0.004$ ).

Conclusions: About $80 \%$ of preterm VLBW infants have insufficient $25 \mathrm{OHD}$ levels during early postnatal life; about $25 \%$ remain insufficient at follow-up assessment. A higher level of supplementation is warranted in those infants.

[i] Misra et al. Vitamin D deficiency in children and its management: review of current knowledge and recommendations. Pediatrics 2008;122;398-417.

\section{INFLUENCE OF COW'S MILK INTAKE DURING THE COMPLEMENTARY FEEDING PERIOD ON INFANTS' INFECTIOUS AND ALLERGIC MORBIDITY}

S. Nyankovskyy, O. Ivakhnenko, D. Dobryanskyy

Paediatrics, L'viv National Medical University, L'viv, Ukraine

It has been suggested that cow's milk intake during the complementary feeding period could negatively affect the health status of infants and toddlers. The objective of this study was to evaluate the possible influence of complementary diet containing whole cow's milk on infants' infectious and allergic morbidity.

Methods: The health status of 1158 term infants aged from 10 to 12 months has been evaluated in a cross-sectional study. 612 of them (53\%) received whole cow's milk as a complementary feeding product (cow's milk group) and $546(47 \%)$ were not (control group). During the study period serial physical assessments, medical record reviews have been performed and special questionnaire has been used. The incidences of intestinal, respiratory tract infections and any allergic manifestations were compared between the groups.

Results: The groups were not different in terms of age and growth parameters at evaluation. The average period of breastfeeding in infants from the control group was significantly longer than in infants who received whole cow's milk $(6,4 \pm 3,3$ months vs. 4,98 $\pm 2,58$ months; $p<0,0001)$. In comparison with the control group infants fed with cow's milk had reliably higher incidences of intestinal (adjusted for breastfeeding duration OR 2,021; $95 \% \mathrm{Cl} 1,56$ 2,62 ) and respiratory infections (adjusted OR 1,43; $95 \% \mathrm{Cl} 1,12-1,84)$ as well as the higher risk for any allergic reactions (adjusted OR 1,89; 95\% Cl 1,422,51).

Conclusions: Our data suggest that feeding with whole cow's milk during the first year of life could increase infants' infectious and allergic morbidity. 